\section{BRAZIULIAN JOURNAL \\ OF MEDICAL AND BIOLOGICAL RESHARCH}

www.bjournal.com.br
ISSN 0100-879X

Volume 43 (11) 1010-1134 November 2010

BIOMEDICAL SCIENCES

AND

CLINICAL INVESTIGATION

Braz J Med Biol Res, November 2010, Volume 43(11) 1123-1126

doi: 10.1590/S0100-879X2010007500104

Effects of isoflavone on the learning and memory of women in menopause: a double-blind placebo-controlled study

R.F. Santos-Galduróz, J.C.F. Galduróz, R.L. Facco, H. Hachul and S. Tufik

The Brazilian Journal of Medical and Biological Research is partially financed by

遗CNPq

Ministério

da Ciência e Tecnologia

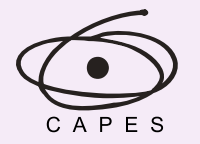

Ministério da Educação

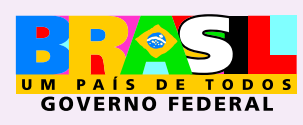

GOVERNO FEDERAL
DFAPESP

Institutional Sponsors
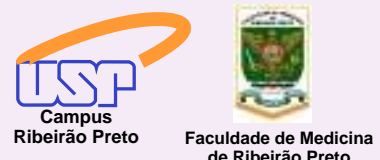

Ф SHIMADZU

GE Healthcare
Hotsite of proteomics metabolomics developped by: 


\title{
Effects of isoflavone on the learning and memory of women in menopause: a double-blind placebo-controlled study
}

\author{
R.F. Santos-Galduróz ${ }^{1,2}$, J.C.F. Galduróz ${ }^{3}$, R.L. Facco ${ }^{4}$, H. Hachul ${ }^{3}$ and S. Tufik ${ }^{3}$ \\ ${ }^{1}$ Departamento de Biociências, Universidade Estadual Paulista, Rio Claro, SP, Brasil \\ ${ }^{2}$ Centro de Matemática, Computação e Cognição, Universidade Federal do ABC, Santo André, SP, Brasil \\ ${ }^{3}$ Departamento de Psicobiologia, Universidade Federal de São Paulo, São Paulo, SP, Brasil \\ ${ }^{4}$ Independent researcher in private practice, São Paulo, SP, Brasil
}

\begin{abstract}
Hormone decline is common to all women during aging and, associated with other factors, leads to cognitive impairment. Its replacement enhances cognitive performance, but not all women present a clinical and family or personal history that justifies its use, mainly women with a history of cancer. The aim of this study was to determine whether a daily oral dose of $80 \mathrm{mg}$ of isoflavone extract for 4 months can produce benefits in women with low hormone levels, contributing to improvement in cognitive aspects. The sample comprised 50 - to 65-year-old women whose menstruation had ceased at least 1 year before and who had not undergone hormone replacement. The volunteers were allocated to two groups of 19 individuals each, i.e., isoflavone and placebo. There was a weak correlation between menopause duration and low performance in the capacity to manipulate information (central executive). We observed an increase in the capacity to integrate information in the group treated with isoflavone, but no improvement in the capacity to form new memories. We did not observe differences between groups in terms of signs and symptoms suggestive of depression according to the Geriatric Depression Scale. Our results point to a possible beneficial effect of isoflavone on some abilities of the central executive. These effects could also contribute to minimizing the impact of memory impairment. Further research based on controlled clinical trials is necessary to reach consistent conclusions.
\end{abstract}

Key words: Isoflavone; Cognitive disorders; Aging; Information integration; Memory; Menopause

\section{Introduction}

Estrogen receptors affect several neurotransmission systems in many areas, including the catecholaminergic, serotoninergic and gabaergic ones, interfering with cognitive functioning. One of the actions of estrogen is to enhance the density of the dendritic spines in the neurons of the CA1 area in the hippocampus (1). Progesterone contributes to the same action within 6-8 $\mathrm{h}$ of ingestion, and returns to basal levels rapidly (2).

Estrogen increases the concentration of acetylcholine transferase, an enzyme that synthesizes acetylcholine, the neurotransmitter involved in memory functions. Furthermore, neurotrophic effects of estrogen may explain how this hormone could have a protective action against cognitive deficit during aging $(3,4)$.

Hormone decline is common to all women during aging and, associated with other factors, leads to cognitive impairment, especially regarding memory. Its replacement enhances cognitive performance, but not all women present a clinical and family or personal history that justifies its use, mainly women with a history of cancer (5-7).

Isoflavone is a compound present in soy with a chemical structure similar to that of estrogen, hence the interest in its use as an alternative substance to alleviate the effects of menopause (8). Even though several studies have shown the influence of isoflavone on cognitive performance, the results are still quite contradictory. A review by Zhao and Brinton (9) of the literature published between 2000 and 2007 showed only seven studies that analyzed the effects of isoflavones on the cognition of postmenopausal women. Among the factors justifying the discrepancies in the results of different studies, the authors cite variations in the composition of phytoestrogen, length of administration, design of the studies and heterogeneity of the populations studied, suggesting the need for more randomized placebo-

Correspondence: J.C.F. Galduróz, R. Napoleão de Barros, 925, 04024-000 São Paulo, SP, Brasil. E-mail: galduroz@psicobio.epm.br

Received February 25, 2010. Accepted September 23, 2010. Available online October 8, 2010. Published November $12,2010$. 
controlled studies.

The objective of the present study was to evaluate the effect of isoflavone on the cognition of post-menopausal women through a randomized placebo-controlled study conducted on a group of women having similar folliclestimulating hormone (FSH) levels.

\section{Material and Methods}

\section{Subjects}

The inclusion criteria were 50- to 65-year-old women whose menstruation had ceased at least 1 year before and whose serum FSH concentrations were over $30 \mathrm{mIU} / \mathrm{mL}$, and who had not undergone hormone therapy and were not taking any hypnotic medication. Volunteers with scores below 10 on the Geriatric Depression Scale were invited to participate in the study. Randomization was performed by a third researcher and patients were allocated to two groups of 19 individuals each, i.e., isoflavone and placebo groups. Treatment consisted of the ingestion of one pill a day over a period of 4 months. The tablets of Fisiogen ${ }^{\circledR}$ (provided by the Zambon Group, Italy) contained $80 \mathrm{mg}$ isoflavone (60.8 $\mathrm{mg}$ genistein, $16 \mathrm{mg}$ daidzein, and $3.2 \mathrm{mg}$ glycitein). The placebo group received similar pills, which did not contain the active pharmaceutical ingredient. After 4 months of treatment, the patients were submitted to the same clinical assessment. Patients had a monthly consultation, when medication for the subsequent month was supplied, and they were inquired as to their clinical complaints.

The groups were matched for age (54.4 \pm 4.3 and 56.6 \pm 3.6 years, isoflavone and placebo, respectively), age at onset of menopause $(48.3 \pm 3.3$ and $48.2 \pm 5.3$ years, isoflavone and placebo, respectively) and the duration of menopause $(5.6 \pm 4.6$ and 8.2.6 \pm 6.7 years, isoflavone and placebo, respectively).

\section{Clinical assessment}

The following instruments were used for the cognitive evaluation: Visual-Spatial test; Digit span of the Wechsler Adult Intelligence Scale III (WAIS-III) to evaluate short-term memory and the capacity to manipulate information (central executive); Digit symbol (WAIS-III) to evaluate agility and attention; Similarity (WAIS-III) to evaluate the capacity to integrate information; Verbal Paired Associates (WMS-R) to evaluate the declarative episodic memory, integration of information and learning of verbal content (10); Geriatric Depression Scale (GDS) to evaluate depression (11).

The same examiner applied the tests and neuropsychological tests, being blind to the substances administered during the experiment.

\section{Statistical analysis}

The Student $t$-test for independent samples was used to compare the groups before and after intervention and effect size to evaluate the degree of juxtaposition of the samples. The chi-square test was used to compare the number of volunteers in both groups who had not learned the tasks during the trials of the Verbal Paired Associates. The comparison of the number of recalls of the groups, considering the type of stimulus (with or without semantic relation) during the trials was performed by three-way ANOVA for repeated measures and by the Pearson test to evaluate possible correlations between parameters. Significance was set at $P<0.05$ and the Statistica 5.0 software was used for all analyses.

The research protocol was approved by the Ethics Committee of UNIFESP/EPM (Protocol \#0564/02) and all subjects gave written informed consent to participate in the study.

\section{Results}

Although we controlled the variables that affect cognitive performance, after the code was opened up (double blind) we observed that, at baseline, the groups were significantly different in some cognitive variables, and this is the reason why we chose to use the delta in the final analysis. The analysis showed a negative correlation between menopause duration and the number of items recalled in the reverse order test of the Digit span $(r=-0.37 ; P<0.05)$.

We observed differences between the performance of the groups in semantically related pairs in the first and the second trials of the Verbal Paired Associates test and in the number of delayed recalls $(P=0.04$; Table 1$)$. The delta scores regarding the total number of words in the delayed recall showed statistically significant differences between groups only in the semantically non-related pairs, that is, the placebo group presented a decrease in the number of recalls while the experimental group presented no changes $(P=0.02)$. No differences were detected regarding the performance in the Test of Free Recall of Word Pairs between the placebo and the isoflavone groups $(P=0.06)$.

In terms of the number of volunteers per group who had not acquired the pairs of words along the trials, we found no statistically significant differences when we compared the pre- and post-treatment results for the placebo group.

\section{Discussion}

Even though this was a randomized study, when it was over we realized that the groups were statistically different in terms of cognitive and mood variables. Therefore, we decided to use the delta for the analysis of treatment effects.

There was a weak correlation between menopause duration and low performance in the capacity to manipulate information (central executive). On the other hand, we observed better results in the capacity to integrate information in the group treated with isoflavone (recall of semantically related words), but no improvement in the capacity to form 
Table 1. Comparison of the delta scores between groups regarding cognitive variables.

\begin{tabular}{|c|c|c|c|c|}
\hline & \multicolumn{2}{|c|}{ Placebo } & \multicolumn{2}{|c|}{ Isoflavone } \\
\hline & Mean & SD & Mean & SD \\
\hline Visual-spatial test & 0.1 & 1.1 & -0.1 & 2.3 \\
\hline GDS & -5.1 & 5.9 & -2.7 & 5.2 \\
\hline \multicolumn{5}{|l|}{ WAIS-III } \\
\hline Digit symbol & 1.5 & 8.0 & 2.6 & 7.4 \\
\hline Digit forward & -0.2 & 1.0 & -0.2 & 1.1 \\
\hline Digit backward & 0.5 & 1.1 & 0.9 & 1.4 \\
\hline Similarity & 0.2 & 3.4 & 1.3 & 3.5 \\
\hline \multicolumn{5}{|l|}{ Verbal Paired Associates - WMS-R } \\
\hline \multicolumn{5}{|l|}{ With semantic relation } \\
\hline Trial 1 & 0.8 & 1.1 & $1.6^{*}$ & 1.1 \\
\hline Trial 2 & 0.2 & 1.0 & $1.3^{*}$ & 1.2 \\
\hline Delayed recall & 0.1 & 0.2 & 0.4 & 0.7 \\
\hline \multicolumn{5}{|l|}{ Without semantic relation } \\
\hline Trial 1 & 0.8 & 1.1 & 0.5 & 0.5 \\
\hline Trial 2 & 1.0 & 1.9 & 0.6 & 0.8 \\
\hline Delayed recall & 0 & 0.9 & $1.2^{*}$ & 1.6 \\
\hline \multicolumn{5}{|l|}{ Learning word pairs } \\
\hline $\begin{array}{l}\text { Difference in the number of items recalled from the } 1 \text { st to the } \\
2 \text { nd trial in the semantically related pairs }\end{array}$ & -0.1 & 0.3 & 0.1 & 0.5 \\
\hline $\begin{array}{l}\text { Difference in the number of items recalled from the 1st to the } \\
2 \text { nd trial in the pairs without semantic relation }\end{array}$ & -1.0 & 1.4 & 0.3 & 1.3 \\
\hline
\end{tabular}

GDS $=$ Geriatric Depression Scale; WAIS-III = Wechsler Adult Intelligence Scale III. ${ }^{*} \mathrm{P}<0.05$, isoflavone compared to placebo (Student $t$-test for independent samples).

new memories (episodic declarative memory). These results agree with those obtained by other investigators (12-14).

Our results point to a possible beneficial effect of isoflavone on some abilities of the central executive (e.g., manipulation and integration of information). These effects could also contribute to minimizing the impact of memory impairment. There was a possible stabilization of memory decay, i.e., recall capacity, but storing capacity remained limited. Barrett-Connor and Kritz-Silverstein (15) detected similar results.

Finally, visual-spatial abilities did not present significant differences, as in the study of Ditkoff et al. (16) with hormone replacement therapy.

The review of Lee et al. (17) evaluated the metabolism of soy isoflavones and their action on cognition function by mimicking the effects of estrogen on the central nervous system. Estrogen affects neuron survival and growth, synaptic plasticity and brain function through its antioxidant properties. Genistein and other soy isoflavones may act in a similar manner because they also exhibit estrogenic activity. Moreover, soy isoflavones stimulate the activity of choline acetyltransferase. The estrogenic effects of soy isoflavones appear to be dose dependent. However, the dose administered may not reflect the uptake by the central nervous system, since isoflavones in foods and supplements are highly water-soluble glucosides, and therefore have to be processed by intestinal $\beta$-glucosidases to release bioactive aglycons (daidzein, genistein and glycitein). Daidzein needs to be further processed to release the estrogenic and biologically active metabolite, equol. Several studies have demonstrated wide variation in the intestinal metabolism of soy isoflavones, regardless of the volunteers' age, even when the dose is standardized (18). This variation may account for the divergent results in terms of cognitive improvement reported in the literature.

Considering these conflicting results in the literature, further research based on controlled clinical trials is necessary to yield consistent conclusions.

\section{Acknowledgments}

Research supported by AFIP and CNPq. 


\section{References}

1. McLaughlin KJ, Bimonte-Nelson H, Neisewander JL, Conrad $C D$. Assessment of estradiol influence on spatial tasks and hippocampal CA1 spines: evidence that the duration of hormone deprivation after ovariectomy compromises 17beta-estradiol effectiveness in altering CA1 spines. Horm Behav 2008; 54: 386-395.

2. Williams AE, Maskarinec G, Hebshi S, Oshiro C, Murphy S, Franke AA. Validation of a soy questionnaire with repeated dietary recalls and urinary isoflavone assessments over one year. Nutr Cancer 2003; 47: 118-125.

3. Sherwin BB. Menopause, early aging, and elderly women. In: Jensvold MF, Halbreich U, Hamilton JA (Editors), Psychopharmacology and women - sex, gender and hormones. Washington: American Psychiatric; 1996. p 225-237.

4. Matsuda $\mathrm{Y}$, Hirano $\mathrm{H}$, Watanabe $\mathrm{Y}$. Effects of estrogen on acetylcholine release in frontal cortex of female rats: involvement of serotonergic neuronal systems. Brain Res 2002; 937: 58-65.

5. Becker S, Kaaks R. Exogenous and endogenous hormones, mammographic density and breast cancer risk: can mammographic density be considered an intermediate marker of risk? Recent Results Cancer Res 2009; 181: 135-157.

6. Brewster DH, Sharpe KH, Clark DI, Collins J. Declining breast cancer incidence and decreased HRT use. Lancet 2009; 373: 459-460.

7. Pilsakova L, Riecansky I, Ostatnikova D, Jagla F. Missing evidence for the effect one-week phytoestrogen-rich diet on mental rotation in two dimensions. Neuro Endocrinol Lett 2009; 30: 125-130.

8. Islam F, Sparkes C, Roodenrys S, Astheimer L. Short-term changes in endogenous estrogen levels and consumption of soy isoflavones affect working and verbal memory in young adult females. Nutr Neurosci 2008; 11: 251-262.

9. Zhao L, Brinton RD. WHI and WHIMS follow-up and human studies of soy isoflavones on cognition. Expert Rev Neurother 2007; 7: 1549-1564.

10. Lezak MD. Neuropsychological assessment. 3rd edn. New York: Oxford University; 1995.

11. Yesavage JA, Brink TL, Rose TL, Lum O, Huang V, Adey $M B$, et al. Development and validation of a geriatric depression screening scale: A preliminary report. $J$ Psychiatric Res 1983; 17: 37-49.

12. Kreijkamp-Kaspers $S$, Kok L, Grobbee DE, de Haan EH, Aleman A, van der Schouw YT. Dietary phytoestrogen intake and cognitive function in older women. $J$ Gerontol A Biol Sci Med Sci 2007; 62: 556-562.

13. Fournier LR, Ryan Borchers TA, Robison LM, Wiediger M, Park JS, Chew BP, et al. The effects of soy milk and isoflavone supplements on cognitive performance in healthy, postmenopausal women. J Nutr Health Aging 2007; 11: 155-164.

14. Schmidt R, Fazekas F, Reinhart B, Kapeller P, Fazekas G, Offenbacher $\mathrm{H}$, et al. Estrogen replacement therapy in older women: a neuropsychological and brain MRI study. J Am Geriatr Soc 1996; 44: 1307-1313.

15. Barrett-Connor E, Kritz-Silverstein D. Estrogen replacement therapy and cognitive function in older women. JAMA 1993; 269: 2637-2641.

16. Ditkoff EC, Crary WG, Cristo M, Lobo RA. Estrogen improves psychological function in asymptomatic postmenopausal women. Obstet Gynecol 1991; 78: 991-995.

17. Lee YB, Lee HJ, Sohn HS. Soy isoflavones and cognitive function. J Nutr Biochem 2005; 16: 641-649.

18. Gleason CE, Carlsson CM, Barnet JH, Meade SA, Setchell $\mathrm{KD}$, Atwood CS, et al. A preliminary study of the safety, feasibility and cognitive efficacy of soy isoflavone supplements in older men and women. Age Ageing 2009; 38: 86-93. 